\title{
Comunicação e gestão de resíduos sólidos: um estudo sobre políticas de comunicação ambiental na UERJ
}

Communication and solid waste management: a study of environmental communication policies at the State University of Rio de Janeiro

\section{Introdução}

Este artigo traz o detalhamento técnico e os primeiros resultados do projeto de extensão "Comunicação e gestão de resíduos sólidos: um estudo sobre políticas de comunicação ambiental na UERJ", nomeado posteriormente por seus participantes de COMGERES - Comunicação em Gestão de Resíduos. O projeto, iniciado em junho de 2010, conta com o apoio da Sub-Reitoria de Extensão e Cultura (SR-3) e obteve os resultados de sua primeira fase no mês de dezembro de 2010.

A partir do resgate da problemática da gestão de resíduos da nossa cidade, especificamente da Universidade do Estado do Rio de Janeiro (UERJ), a Faculdade de Comunicação Social planejou diagnosticar as percepções sociais sobre o tema e por em prática uma maneira eficaz e dialógica de intervir nesta problemática junto à sociedade.

O lixo se tornou, nos últimos anos, um dos principais temas no debate de assuntos públicos. Presente nas ruas, acumulado nas esquinas, visível a todos, os restos molestam aos que passam por perto. Os montes de sobras alteram a estética da cidade, tornando-a feia, desorganizada e de aspecto indesejável. A imagem dos resíduos causa vergonha. Ainda que parte integrante do mecanismo de sobrevivência da espécie humana, a relação do homem com o lixo sempre foi uma dificuldade a ser vencida. Ao longo da história, os dejetos têm se tornado um problema para a vida em sociedade, pois não se sabe exatamente o que fazer com ele.

Segundo Rosana Miziara ${ }^{1}$, no Brasil, a preocupação concreta com os resíduos começa no início do século XIX, quando, por causa das epidemias, estabeleceram-se normas para a sua disposição. Examinar a questão do lixo, de acordo com

\author{
Ricardo Ferreira Freitas', Livia Abdalla ${ }^{2}$, \\ Isabela Costa ${ }^{3}$
}

\begin{abstract}
Resumo
O presente artigo apresenta os primeiros resultados do projeto de extensão "Comunicação e gestão de resíduos sólidos: um estudo sobre políticas de comunicação ambiental na UERJ", que tem o apoio da Sub-Reitoria de Extensão e Cultura (SR-3). O projeto objetiva a investigação, o planejamento e a posterior implementação de uma política de comunicação ambiental na Universidade, especialmente pelo seu caráter irradiador de comportamento e saber. A comunicação, através dos seus mecanismos de estabelecimento de diálogo com a sociedade e análise de atitudes e disposições mentais expressas na opinião pública, pretende buscar a melhor maneira de informar e conscientizar a comunidade interna da UERJ quanto a um gerenciamento mais consciente da disposição dos resíduos gerados na instituição.

Palavras-chaves: Comunicação; Educação; Meio ambiente
\end{abstract}

Área Temática: Comunicação Linha de Extensão: Questões ambientais; Resíduos Sólidos
I' Vice-diretor e Professor da FCS. UERJ. E-mail: rfreitas@uerj.br
${ }^{2}$ Bolsista PROATEC e supervisora do projeto COMGERES. UERJ.
E-mail: livia.abdalla@gmail.com
32 Aluna de graduação. UERJ. E-mail: isaumcosta@gmail.com 
a autora, revela não somente os estilos de vida e costumes da época, mas também as inter-relações institucionais do período.

Uma das grandes questões relativas a esta problemática nos dias atuais é a excessiva produção de lixo e, consequentemente, a impossibilidade de seu adequado manejo. A gestão dos resíduos sólidos representa hoje um dos maiores problemas sociais, afetando as esferas econômicas, política e ambiental.

\section{Consumo e gestão de resíduos}

A industrialização, a partir do século XIX, gerou uma mudança profunda na velocidade de fabricação dos produtos, aumentando a quantidade disponível no mercado. Por sua vez, o consumo, mecanismo necessário para dar destino aos itens originários da produção configura-se como a etapa final deste processo. É através do consumo que o produto consolida sua identidade, afinal, este somente se torna um produto ao ser consumido. $\mathrm{O}$ ato de consumir surge, portanto, como ação social engendrada e necessária ao sistema produtivo industrial, sem a qual os produtos perdem sua razão de existir. Como nos dizia Marx, "sem produção não há consumo; mas sem consumo também não haveria produção, porque neste caso a produção não teria nenhum objetivo" ${ }^{2}$.

Base de sustento da produção industrial, o consumo se afirmou, nas últimas décadas, como motor da manutenção e do crescimento da produção de bens materiais. Sabemos, portanto, que o consumo vai muito além da aquisição de objetos necessários a sobrevivência humana, e está cada vez mais ligado a um sistema social que o tem como elemento central de funcionamento. Vivemos a "revolução consumista" rico em que o consumo se torna o objetivo final de todo o indivíduo, razão para a existência, mediação das relações sociais e sustento do convívio humano. De acordo com Bauman:

De maneira distinta do consumo, que é basicamente uma característica e uma ocupação dos seres humanos como indivíduos, o consumismo é um atributo da sociedade. (...) A questão que exige uma investigação mais atenta diz respeito ao que 'queremos', 'desejamos' e 'almejamos', e como a substância de nossas vontades, desejos e anseios estão mudando no curso e em consequência da passagem ao consumismo.
O consumismo passa a atrelar a felicidade não somente à satisfação das necessidades básicas de sobrevivência, mas a uma crescente e constante intensidade de desejos e necessidades, saciados na medida em que se consome um novo objeto. Portanto, não falamos de uma simples compra, mas sim da aquisição de um novo objeto, que seja melhor que o anterior e o substitua. A saciedade dos desejos dos quais nos fala Bauman, depende de um fluxo contínuo de novos produtos no mercado, ao passo que estes perdem o "brilho" muito rapidamente. A lógica do consumismo traz em si, uma obsolescência embutida, apontando para um momento único na história do descarte dos produtos e, consequentemente, na produção dos resíduos pós-consumo.

Ao unirmos as características sociais e psicológicas trazidas pelo fenômeno do consumismo à necessidade constante de lucro das empresas, a sociedade capitalista impulsiona um aumento de objetos/alimentos, gerado a partir do incentivo ao consumo supérfluo para atender a demandas de mercado. Como nos explica a profissional de Relações Públicas Maria José Oliveira4:

Vivemos em uma sociedade industrial capitalista, na qual nossos desejos, gostos e vontades são, na verdade, condicionados para manter constantes os fluxos do processo produtivo. Existimos enquanto consumidores porque somos continuamente recriados pela produção de sempre novas mercadorias. As mercadorias tornam-se sujeitos porque não são apenas objetos oferecidos ao consumidor, elas são a própria necessidade fabricada em forma de Coisas.

A grande geração e consumo de produtos fazem com que não só o lixo aumente em quantidade, mas também diversifique a sua qualidade, uma vez que as tecnologias colocaram na esteira de produção uma gama de novos materiais. Enquanto que, no passado, a base dos resíduos gerados era orgânica, hoje temos uma grande parcela de sintéticos, em alguns casos não recicláveis, que geram uma série de prejuízos ao meio ambiente. Assim, conjugar desenvolvimento econômico e preservação do meio ambiente tornou-se um grande desafio para o mundo contemporâneo. Os indivíduos desejam os objetos com a mesma rapidez que os jogam foram, vivemos a era dos "descartáveis", incentivada pelas mensagens de comunicação.

Um desafio ainda maior é reorganizar o comportamento das pessoas com relação à gestão dos 
resíduos produzidos na etapa do pós-consumo. $\mathrm{O}$ contexto ambiental mudou e os indivíduos hoje desconhecem os danos causados ao meio ambiente pela forma como consomem qualitativa e quantitativamente, bem como sobre os novos processos de coleta/seleção e tratamentos dos vários tipos de lixo produzidos pela sociedade. Ou seja, a população não tem conhecimento das externalidades do processo produtivo e, além disso, desconhece o que é possível fazer hoje para, em primeiro lugar, reduzir a produção de resíduos; em segundo, como e quais produtos podem ser reutilizados e como, onde e quais podem ser reciclados.

É necessária uma política concreta de gestão integrada de resíduos, aliada a uma rede clara de informações sobre os seus benefícios e que possa ser executada com gestos simples, criando um embrião para uma cultura de consumo sustentável.

No nosso país a produção excessiva de lixo é um problema que cresce exponencialmente. A enorme geração de resíduos aparece claramente nos dados do censo de 2000 do IBGE - Instituto Brasileiro de Geografia e Estatística. O Brasil produz aproximadamente 230 mil toneladas por dia, sendo cerca de 13 mil toneladas geradas na região metropolitana do Rio de Janeiro ${ }^{5}$. Desse total nacional, 37\% são jogados em aterros controlados, $36,2 \%$ em aterros sanitários e $25 \%$ em vazadouros a céu aberto (lixões). No caso do Rio de Janeiro, são cerca de $51 \%$ para os aterros sanitários, 25\% para os lixões e $23 \%$ para os aterros controlados. Ainda que haja uma grande diferença entre esses tipos de depósitos ${ }^{6}$, os três modelos oferecem possibilidade de danos, muitas vezes irreparáveis, ao meio ambiente.

Esses grandes depósitos situam-se fora do olhar do morador comum e, ao se jogar os seus dejetos na lixeira doméstica ou deixar na rua para o caminhão coletor recolher, tem-se a impressão de que "somem". Mas essa é uma ilusão que paulatinamente tem se apagado pelo aumento do volume de resíduos gerados e a impossibilidade da transformação dos resíduos.

\section{Comunicação e pós-consumo}

Como citamos anteriormente, existe hoje um fenômeno social que nos incita constantemente ao consumo e este mecanismo é sustentado, em grande medida, pela ação da publicidade.
A publicidade, através de suas técnicas de persuasão, trabalha com valores simbólicos que atuam no querer e no desejo dos indivíduos. Tais valores são reforçados constantemente pelas esferas de pertencimento e identidade, terrenos há tempos habitados pelo funcionamento do consumo.

A lógica publicitária reforça a subjetivação das mercadorias, transformando-as em artigos sedutores e com vida própria, reforçando o conceito de "fetichismo da mercadoria" de Marx? ${ }^{7}$ Nele, as mercadorias se tornam sujeitos do processo social e passam a ter mais importância do que os próprios indivíduos. Ao adquirirem uma essência viva, as mercadorias são apresentadas em sua forma presente, descoladas de seu processo produtivo anterior e posterior e passam a espelhar somente a vontade dos indivíduos em adquiri-las.

A comunicação, entendida por um número importante de instituições públicas e privadas no Brasil como um instrumento de difusão, exerce o trabalho principal de divulgar as mensagens com a preocupação essencial de persuadir e convencer o consumo destas mercadorias. O fim é em grande medida de caráter comercial. São sistemas de comunicação que reafirmam os códigos simbólicos dominantes e trabalham em linha estrita de manutenção dos sistemas político, social e econômico vigentes. Dessa forma, as mensagens de comunicação em geral, e as publicitárias especificamente, atuam como suporte à lógica de consumo e obsolescência contínua.

Existe uma radical diferença entre o uso da informação em sua dimensão persuasiva propagandística e o uso da autêntica comunicação: horizontal, educativa, participativa, dialógica e liberadora. Uma comunicação que vise à mudança social e à melhoria de vida deve ter como premissa uma relação bidirecional com seu público e estabeleça com ele um diálogo, criando condições para uma ação participativa, que garanta resultados efetivos. É preciso que cada indivíduo se sinta parte integrante de um sistema que lhe confere voz, para que assim assuma sua condição de sujeito histórico de transformação.

De acordo com o educador Paulo Freire ${ }^{8}$, a comunicação é uma relação horizontal de A + B, nasce de una matriz crítica e gera crítica, se nutre de amor, de humildade, de esperança, de fé e de confiança. Por isso, só o diálogo comunica. E quando os polos do diálogo se ligam assim, com 
amor, esperança e fé um no outro, se fazem críticos em busca de algo. Cria-se, então, uma relação de empatia entre ambos. Só então há comunicação.

No caso do pós-consumo, as mensagens midiáticas, além de promover o aumento dos resíduos, uma vez que incitam o descarte, não abordam o que acontece com estes produtos depois que eles são descartados. Seu destino final, o dano causado ao meio ambiente, bem como o que hoje existe de tecnologia, processos e tratamentos dos resíduos produzidos são desconhecidos do grande público.

Além disso, a divulgação da problemática dos resíduos, quando acontece, é feita de forma a responsabilizar o consumidor, promovendo "receitas" para que o mesmo prejudique menos o meio ambiente. Em reportagem da Folha de São Paulo de fevereiro de $2000^{4}$, são apresentados os dez mandamentos do consumidor consciente, segundo dados da Environmental Protection Agency (EPA), a Agência de Proteção Ambiental dos Estados Unidos. A lista, de 10 itens, contém premissas como, por exemplo: comprar produtos que tenham refil, evitar produtos descartáveis, comprar produtos que a embalagem possa ser reutilizada, procurar comprar baterias e pilhas recarregáveis, evitar usar produtos descartáveis, entre outros. No entanto, quando o consumidor chega ao supermercado, não sabe como encontrar os produtos ditos "ecologicamente responsáveis", nem como descartá-los corretamente e, mais grave, não tem o conhecimento do processo que esses produtos irão percorrer até serem reciclados ou ainda se de fato serão, já que esta informação não retorna para ele.

Outro exemplo interessante nos traz Mizia$\mathrm{ra}^{1}$, ao mencionar os anúncios e cartilhas dos anos 1970 que traziam o personagem "Sujismundo" como representante de todos os maus hábitos de higiene e limpeza com o slogan "Povo desenvolvido é povo limpo". O personagem por sua simpatia acabou por conquistar a audiência e gerou algumas controvérsias sobre se não estaria, contrariamente ao objetivo da campanha, incentivando a produção de lixo.

Segundo a autora, as campanhas culpabilizavam somente o consumidor que sujava a cidade, sem mencionar a ação do Estado, ausente no discurso. E ainda, as empresas de limpeza se colocavam como benfeitoras, porque contribuíam para a limpeza da cidade e a melhoria da qualidade de vida. Campanhas como essas "educam" o consumi- dor, mas não atuam no que pode ser seu principal problema, a falta de conhecimento, por não serem pensadas tendo em conta as opiniões, dúvidas e interesses do público para o qual são dirigidas.

\section{Objetivo do projeto}

O principal objetivo é a realização de uma campanha de educação ambiental para que os indivíduos tomem conhecimento da situação socioambiental em que se encontram e modifiquem seu comportamento com relação a ela, com o fim de aperfeiçoá-la. Além disso, pretende-se trazer à tona uma nova visão político-ideológica, tangível, através de ações e programas que se desenvolvam em conjunto com a universidade, promovendo a noção de que o meio ambiente existe em vários níveis, do individual ao universal.

Por fim, busca-se transformar os diferentes tipos de públicos pertencentes à instituição em agentes atuantes na melhoria do meio ambiente e do processo de comunicação, ou seja, porta-vozes da conscientização ambiental.

\section{Metodologia}

A primeira fase do projeto foi realizada e envolveu um diagnóstico sobre o conhecimento da população circulante do campus Maracanã, a respeito da forma de disposição do lixo e das consequências desse processo para a sociedade e para o meio ambiente.

No período de julho a setembro de 2010, foram entrevistadas 200 pessoas entre alunos e funcionários da universidade, com o intuito de saber o que eles pensam e fazem em relação ao meio ambiente, principalmente no que diz respeito à gestão de resíduos sólidos. A pesquisa abordou assuntos gerais como renda, idade, fonte de informações e hábitos na Internet, e também apurou o quanto os entrevistados conheciam sobre temas como ecologia, sustentabilidade e responsabilidade social.

A metodologia empregada foi a da Pesquisa Estatística Descritiva e o instrumento formal de coleta de dados foi o questionário, desenvolvido pelo Laboratório de Pesquisa Mercadológica e de Opinião Pública (LPO) da UERJ. A amostragem foi randômica, por meio da qual qualquer elemento dentre o universo selecionado tem a 
mesma possibilidade de ser escolhido para fazer parte da amostra.

$\mathrm{Na}$ segunda fase do projeto, que agora se inicia, objetiva-se fazer a análise dos dados da pesquisa e, a partir desses parâmetros, definir: quais informações devem constar na campanha, quais mecanismos de comunicação devem ser utilizados, qual a melhor forma de abordagem dos conteúdos e qual(is) outra(s) atividade(s) pode $(\mathrm{m})$ ser realizada(s) para melhor qualidade dos resultados.

\section{Resultados}

Desde seu início, o projeto conta com um website institucional, que além de informações sobre o andamento do trabalho, abriga dados sobre a gestão de resíduos no Brasil e no Rio de Janeiro, informações sobre educação ambiental, coleta seletiva e notícias sobre meio ambiente. (www.comgeres.com.br)

Entre os dias 03, 04 e 05 do mês de novembro de 2010, foi apresentado o resultado parcial da pesquisa em um evento realizado no Centro Cultural da UERJ. Na ocasião, foram reunidos profissionais de diversas áreas para a discussão de temas relacionados à gestão de resíduos, como a redução do consumo, o tratamento do lixo, a reutilização e reciclagem de materiais. Especialistas ressaltaram a importância de se refletir sobre estas questões nos dias de hoje e pesquisadores apresentaram projetos que vem sendo desenvolvidos na cidade do Rio de Janeiro. O evento reuniu cerca de 400 participantes por dia entre as atividades de seminário, feira e oficinas, estas últimas contaram com a participação de profissionais e artesãos que trabalham com materiais recicláveis. O evento foi considerado "ótimo" pela maioria dos participantes (80\%).

A pesquisa, primeira fase do projeto aqui descrito, teve, portanto, como resultado, os seguintes dados (aspectos mais relevantes) ${ }^{10}$ :

Perfil dos entrevistados:

- Vínculo com a UERJ: $74 \%$ alunos, 22,5\% funcionários e 3,5\% professores;

- Sexo: $54,5 \%$ feminino, $45,5 \%$ masculino;

- Idade: 35,5\% 20 a 25, 28,5\% 18 a 20 e $20,5 \% 25$ a 35 anos.
Meios pelos quais os entrevistados buscam se informar:

- $61,5 \%$ classificam a Internet como o meio mais importante para se informar;

- $95,5 \%$ acessam internet de casa;

- Dos que acessam redes sociais (96,50\%), $77,49 \%$ acessam com mais frequência o Orkut;

- $34,55 \%$ acessam as redes sociais uma vez ao dia;

- $53,5 \%$ procuram assuntos relacionados ao lazer na web.

Atividades culturais que realiza:

- $53,5 \%$ costumam frequentar cinema e acham a atividade cultural mais importante;

- $34 \%$ frequentam atividades culturais no bairro do Centro;

- $27,5 \%$ frequentam atividades culturais uma vez por mês.

Grau de discordância com as frases dos cartões apresentados:

- $50 \%$ discordaram totalmente da frase: "O crescimento econômico deve ter prioridade sobre todas as outras áreas";

- $62,5 \%$ discordaram totalmente da frase: "Acredito que as mudanças que estão acontecendo no clima são algo da natureza mesmo";

- $26 \%$ discordaram totalmente e $26 \%$ concordaram totalmente com a frase: "O homem é responsável por todos os problemas climáticos do mundo atual";

- $42 \%$ discordaram totalmente da frase: "Acho que qualquer atitude de desenvolvimento é válida para aumentar a riqueza do país".

Opinião sobre meio ambiente:

- $42 \%$ citaram o meio ambiente como um dos principais temas a ser discutido pela sociedade, ficando este em terceiro lugar (70,5\% educação e 45,5\% saúde);

- $16,13 \%$ disseram que "árvore" é a primeira palavra/imagem que vem a cabeça quando se fala em meio ambiente; 
- $70,5 \%$ definiram meio ambiente como "conjunto de todas as formas de vida, no qual uma espécie afeta muitas outras";

- 65\% associaram a frase "É o fornecimento do melhor para as pessoas e para o ambiente, suprindo as necessidades da nossa geração sem afetar a habilidade das gerações futuras de suprir as suas" ao conceito de sustentabilidade;

- $\quad 70,5 \%$ associaram a frase "É o conjunto amplo de ações realizadas por empresas que beneficiam a sociedade, levando em consideração fatores locais, governamentais, econômicos, educacionais, ambientais, de saúde, de transporte e de moradia. Tais ações trazem benefício mútuo para a comunidade e a empresa" ao conceito de responsabilidade social.

Com relação ao descarte de lixo:

- $54,5 \%$ acham que o lixo em sua casa e na cidade é descartado pouco adequadamente. $24 \%$ justificam esta resposta alegando que não há coleta seletiva, 12\% porque não há separação correta do lixo;

- 35\% disseram que lixo é material que pode diminuir custos e ser reutilizado. 28,5\% consideram que são sobras/resíduos.

Conhecimento de reciclagem:

- $100 \%$ conhecem o conceito de reciclagem, $97,5 \%$ de reutilização e $61,5 \%$ o de redução;

- $72,5 \%$ se informam sobre temas ligados ao meio ambiente pela internet. Destes, $22,07 \%$ acessam o site G1. Dos 29,5\% que utilizam jornal para se informar, $57,63 \%$ se informam pelo O Globo. Dos $8 \%$ que utilizam revista para se informar, $68,75 \%$ se informam pela Veja.

Hábitos de consumo:

- $53,5 \%$ levam em conta o preço na hora da compra de um produto. $0 \%$ na possibilidade de que a embalagem do mesmo seja reciclada;

- $51 \%$ utilizam duas sacolas para transportar as compras;

- $88 \%$ não sabem o que é rede solidária;
- $58 \%$ não pensam na reutilização das embalagens no momento da compra do produto. Dos que pensam (42\%), 17,86\% citaram como exemplo a reutilização das embalagens de garrafas pet para armazenar água;

- $67,07 \%$ consideram o preço o fator mais importante para a escolha do combustível de seus carros;

- $62 \%$ tentam reduzir o consumo de um mês para outro;

- $82 \%$ não costumam buscar informações sobre empresas que dizem possuir produtos/serviços sustentáveis (ou ecológicos);

- $75 \%$ não procuram saber se a empresa produtora contribui/respeita o meio ambiente;

- $83,5 \%$ nunca realizaram compras em brechós ou feirão de amigos.

Descarte de produtos:

- $46,5 \%$ descartam as pilhas no lixo comum, $40 \%$ em lixeira própria de coleta seletiva;

- $41 \%$ descartam o óleo de cozinha no ralo da pia, 34\% em garrafas no lixo;

- $46,5 \%$ descartam os eletrônicos por meio de doação;

- $54 \%$ sabem para onde vai o lixo recolhido na cidade. Destes, 54,13\% disseram que o lixo é levado para o lixão;

- 79,5\% não separam o lixo de casa. Destes, $22,64 \%$ alegaram como motivo a falta de coleta seletiva e $16,98 \%$ porque não têm o hábito.

Dos 20,5\% que separam o lixo de casa, $39,02 \%$ não sabem para onde é encaminhado o lixo reciclável de suas casas e 34,15\% acreditam que vai para a associação de moradores/administração do prédio.

UERJ e Meio Ambiente:

- $22,5 \%$ disseram que o lixo produzido na UERJ (com exceção do HUPE e materiais tóxicos) é coletado pela Comlurb sem separação correta. 14\% não sabem;

- $71,5 \%$ procuram se informar sobre temas ligados ao meio ambiente; 
- Dos $28,5 \%$ que não procuram se informar sobre temas ligados ao meio ambiente, 49,12\% não têm interesse sobre o assunto;

- $\quad$ 95,5\% não conhecem a seção "Uerj meio ambiente".

Dúvidas relacionadas ao meio ambiente:

- $58 \%$ possuem dúvidas sobre assuntos ligados ao meio ambiente, sustentabilidade ou ecologia. Destes, 19,83\% citaram coleta seletiva como assunto no qual têm dúvidas, $17,24 \%$ citaram sustentabilidade.

Propagandas:

- $36,5 \%$ disseram que o que mais chama atenção é o ineditismo (coisas diferentes, inusitadas);

- $26,67 \%$ disseram que são ecléticos quanto ao estilo musical;

- $83 \%$ disseram que em um panfleto o que mais lhes chama a atenção é o texto criativo.

\section{Discussão}

A pesquisa revela informações importantes e favoráveis para o desenvolvimento de uma campanha de comunicação ambiental. Inicialmente, existe o reconhecimento de que o meio ambiente é um tema importante a ser discutido, o que abre as portas para se trabalhar o assunto na universidade. As considerações sobre o crescimento econômico e a participação do homem nas mudanças do clima embasam um conteúdo que leva em conta a ação do homem no meio ambiente e a importante preservação da natureza frente ao crescimento econômico desmedido.

Ainda na temática geral, os resultados fortalecem o conceito de meio ambiente como algo que vai do individual ao universal, já que grande parte dos entrevistados reconhece que o termo engloba diferentes formas de vida, que, por sua vez, se afetam umas às outras. Os conceitos de sustentabilidade e de responsabilidade social fecham esta parte conceitual, assumindo que ser sustentável é não afetar as condições futuras de existência e inclui a responsabilidade das empresas na manutenção deste processo.

Com relação ao lixo, os resultados apontam para uma necessidade de reconceituar o termo como sendo algo que pode ser utilizado novamente, seja em sua forma original, seja alterado em sua estrutura química através da reciclagem. É preciso esclarecer que os materiais já utilizados podem ser reinseridos na cadeia produtiva como matéria-prima, gerando riqueza econômica e menos desgaste para o meio ambiente. Os dejetos ainda são vistos por grande parte dos entrevistados como sobra, algo que não tem mais serventia.

Sobre os conceitos próprios da gestão de resíduos, foi evidenciado que há um desconhecimento dos participantes sobre o conceito "redução", o que sugere uma falta de correlação entre consumo e reciclagem, tornando invisível o fato de que os resíduos são resultado de uma cadeia produtiva que relaciona as três atividades: produção, consumo e descarte. Esclarecer essa rede e como ela funciona é de extrema importância para que o consumidor desenvolva uma nova consciência e passe a conhecer, de forma clara, sua participação nesta cadeia.

Especificamente sobre o sistema de coleta seletiva, é preciso trabalhar nas informações sobre quais materiais podem ser reciclados, e como, quando e onde o descarte pode ser feito de maneira correta, dentro e fora da universidade. Ainda são numerosas as dúvidas referentes ao funcionamento da coleta seletiva, que vão desde a separação dos produtos até o destino final que lhes é dado.

Finalmente, sobre as estratégias específicas de comunicação, a Internet aparece como um veículo central na comunicação com o público da universidade, bem como as atividades ligadas a imagens, como a produção de vídeos e a exibição de filmes, visto que a principal atividade cultural dos entrevistados é o cinema.

\section{Conclusão}

Os resultados levantados pelos COMGERES revelam a necessidade de se realizar primeiramente uma comunicação voltada ao corpo administrativo da universidade, já que a instituição não realiza a coleta seletiva de forma sistemática e efetiva. A primeira etapa do plano de comunicação deve, portanto, considerar como públicos-alvo servidores, professores, contratados e empregados terceirizados.

Outra análise nos remete à necessidade de se realizar uma segunda etapa de pesquisa mais 
aprofundada, principalmente no que diz respeito ao descarte de resíduos, uma vez que os hábitos de descarte são um assunto delicado, que possui características não perceptíveis em um primeiro momento, e que merece atenção à subjetividade nele envolvida. Uma possibilidade é a realização de grupos focais de discussão que captem os verdadeiros hábitos de descarte e as razões subjetivas que podem estar ligadas a isso.

Contudo, o objetivo de realização de um diagnóstico - primeira parte do projeto - que provesse informações à campanha de comunicação foi alcançado, na medida em que os dados gerados irão nortear a produção da campanha de educação ambiental, atualmente sendo realizada pelo COMGERES, em parceria com o Laboratório de Comunicação Integrada (LCI), da Faculdade de Comunicação Social.

\section{Contribuição dos autores}

Isabella Costa participou da realização da pesquisa e da redação do artigo.

Livia Maria Abdalla Gonçalves foi a responsável principal pelo desenvolvimento e execução do projeto, pela análise e interpretação dos dados e redação do artigo.

Ricardo Ferreira Freitas participou da redação do artigo e foi responsável pela aprovação final da versão a ser publicada.

\section{Referências}

1. MIZIARA, Rosana. Por uma história do lixo. In: InterfacEHS - Revista de Gestão Integrada em Saúde do Trabalho e Meio Ambiente, v.3 Art. 6, jan/abril. São Paulo: Senac, p.7-8, 2008. Disponível em: http://www.interfacehs.sp.senac.br/index.php/ ITF/article/view/93/118. Acesso em: 02/06/2011.

2. MARX, Karl. O Capital: crítica da economia política. (Os Pensadores) São Paulo, Nova Cultural, p. 235, 1985.

3. BAUMAN, Zygmunt. Vida para o consumo - a transformação das pessoas em mercadoria. Rio de Janeiro, Jorge Zahar, p.38-41, 2008.

4. OLIVEIRA, M. J. C.; NADER, M.S. Comunicação Organizacional e Meio Ambiente: Uma análise sobre a relação entre políticas ambientais e de comunicação. In: Diretor Fundador: Mário de Lucca Erbolato (1982-1990). (Org.). Comunicarte. Campinas: Pontifícia Universidade Católica - PUC Campinas, 2007, v. 26, p.5-41. Disponível em: www.abrapcorp.org.br/anais2007/trabalhos/gt2/gt2_oliveira.pdf. Acesso em: 30/05/2011.

5. IBGE. Pesquisa Nacional de Saneamento Básico. Disponível em: http://www.ibge.gov.br/home/estatistica/populacao/condicaodevida/pnsb/lixo_coletado/lixo_coletado110.shtm. Acesso em: 1/6/2011.
6. Website Ambiente Brasil. Definição de lixão. Disponível em: http://ambientes.ambientebrasil.com.br/residuos/coleta_e_disposicao_do_lixo/lixao_-_residuos.html. Acesso em: 5/6/2011.

7. MARX, Karl. Contribuição à crítica da economia política. São Paulo, Martins Fontes, p.70-79, 2003.

8. FREIRE, Paulo. La educación como práctica de la libertad. España, SigloXXI, pp.103-104, 2007.

9. Website InfanTV. História do personagem Sujismundo. Disponível em: http://www.infantv.com.br/sujismundo.htm. Acesso em: 8/6/2011.

10. Universidade do Estado do Rio de Janeiro. Laboratório de Pesquisa Mercadológica e de Opinião Pública (LPO). Relatório de pesquisa de Opinião sobre Gestão de Resíduos Sólidos. Projeto Comgeres. Disponível em: http://comgeres. com.br/cont/resultados-da-pesquisa/. Acesso em: 10/5/2011.

\begin{abstract}
This article presents the first results of the project "Communication and solid waste management: a study of environmental communication policies at the State University of Rio de Janeiro (UERJ)". The aim of the project is to research, plan, and subsequently implement a policy of environmental communication at the University, focusing on its primary role of spreading knowledge and being a model of behaviour. Communication, through its mechanisms of establishing dialogue with society and analysis of attitudes and mental dispositions expressed in public opinion, intends to find the best way to inform and educate UERJ internal community towards a more conscious management of waste disposal generated by the institution.

Keywords: Communication, Education, Environmental
\end{abstract}

